\title{
Blokların Fraktal Boyutunun Bloklu Piroklastik Kayaların Makaslama Dayanımına Etkisi
}

\author{
Effect of Fractal Dimension of Blocks on the Shear Strength of Blocky Pyroclastic Rocks \\ Elif AVŞAR D \\ Konya Teknik Üniversitesi, Mühendislik ve Doğa Bilimleri Fakültesi, Jeoloji Mühendisliği Bölümü, Konya
}

\section{ÖZ}

$\mathrm{Bu}$ çalışmada, piroklastik çökellerden oluşan bir tür bloklu kaya kütlesinin makaslama dayanımı ile bu kaya kütlesinin içerdiği blokların fraktal boyutu arasındaki ilişkiler araştırılmıştır. Çalışma kapsamında, jeo-mekanik açından "hamurda kaya" olarak tanımlanan bir bloklu piroklastik kaya kütlesinden derlenen örnekler üzerinde üç eksenli makaslama deneyleri uygulanmıştır. Hamurda kayanın kohezyonu (c) ve içsel sürtünme açısı $(\phi)$ değerleri belirlenmiştir. Bununla birlikte, fraktal boyut çözümlemeleri ve sayısal görüntü işleme analizleri yardımıyla hamurda kayanın içerdiği blokların parçalanma fraktal boyutu $\left(D_{F}\right)$ ve pürüzlülük fraktal boyutu $\left(D_{R}\right)$ değerleri hesaplanmıştır. Ayrıca, hamurda kayanın ve bu kaya kütlesinin içerdiği matriks ve blok bileşenlerinin de tek eksenli sıkışma dayanımı değerleri belirlenmiştir. Elde edilen sonuçlara göre, $D_{R}$ ve $D_{F}$ ile $c$ ve $\phi$ arasında pozitif ve negatif doğrusal ilişkilerin olduğu görülmüştür. $\mathrm{D}_{\mathrm{R}}$ ve $\mathrm{D}_{\mathrm{F}}$ değerlerinin her ikisinin de artmasına bağlı olarak $\phi$ değerleri artış gösterirken, c değerlerinin ise azaldığı belirlenmiştir. $D_{R}$ 'nin artmasıyla 'nin artış göstermesi blok yüzeylerinin pürüzlüğünün artmasına bağlı olarak makaslama gerilmelerine karşılık sürtünmenin de arttı̆̆ının işaretidir. Sonuç olarak, $\mathrm{D}_{\mathrm{R}}$ 'nin artmasıyla pürüzlü blok yüzeyleri ile matriks arasındaki temas alanlarının genişlediği ve böylece kaya kütlesini gevşeten zayıflık zonlarının artmasına bağlı olarak kohezyonun azalabileceği sonucuna ulaşılmıştır.

Anahtar Kelimeler: Blok Pürüzlülüğü, Fraktal Boyut, Hamurda Kaya, Makaslama Dayanımı

\begin{abstract}
In this study, the relationships between shear strength of a blocky rock mass consisting of pyroclastic deposits and the fractal dimension of the blocks within the rock mass were investigated. Within the scope, triaxial shear tests were performed on specimens extracted from a blocky pyroclastic rock mass that defined as "bimrock" in terms of jeo-mechanical description. Thereby, cohesion (c) and internal friction angle ( $\phi)$ values of the rock mass were determined. Fragmentation fractal dimension $\left(D_{F}\right)$ and roughness fractal dimension $\left(D_{R}\right)$ values of the blocks within in the rock mass were calculated through the fractal dimension solutions and digital image processing analysis. In addition, uniaxial compressive strength of the rock and the matrix component of this rock mass were determined. The results revealed that there are positive and negative linear relationships between $D_{R}$ and $c$, $\phi$ and between $D_{F}$ and $c$, $\phi$ pairs. It is determined that, while the values of both $D_{R}$ and $D_{F}$ increase, the values of $\phi$ increase and vice versa for cohesion. The increase of $\phi$ with the increase of $D_{R}$ is an indication that the friction also increases by applied shear stresses due to the increase in the roughness of the block surfaces. Finally, the increasing of $D_{R}$ yielded an increase in the sum of the surface areas of the contacts between the matrix and blocks. Thus, the cohesion decreases due to the probable increase of weakness zones that loosen the rock mass.
\end{abstract}

Keywords: Bimrock, Fractal Dimension, Roughness of Blocks, Shear Strength 
Avşar

\section{GíRiș}

Mandelbrot (1967 ve 1982)'un öncü çalışmaları üzerine kurulan ve bilim dünyasında oldukça ilgi gören fraktal geometri drenaj ağları, gözenekli ortamlar, jeolojik yapılar, kanser hücresi araştırmaları, insan fizyolojisi, ekonomi parametreleri, uzay bilimleri vb. olmak üzere çok geniş bir yelpazedeki nesneleri karakterize etmek için kullanılmaktadır. Fraktal sözcük anlamı olarak kırıklı ya da parçalı demektir. Oransal kırılma özelliği gösteren ve farklı ölçeklerde kendini şekilsel olarak tekrar eden geometrik şekiller "fraktal" olarak tanımlanmaktadırlar. Mandelbrot (1967) düzensiz, pürüzlü ve kırıklı geometrideki doğal şekilleri matematiksel olarak tanımlamak amacıyla "Fraktal Boyut, (D)" teorisini geliştirmiş̧tir. Tüm fraktallar kendine benzer ya da en azından istatistiksel olarak kendine benzer özellikler gösterirler. Kendine benzer bir nesnede nesneyi oluşturan parçalar ya da bileşenler cismin bütününe benzer. Düzensiz ayrnntılar ya da desenler giderek küçülen ölçeklerde yinelenir ve tümüyle soyut nesnelerde bu benzerlik sonsuza kadar sürebilir. Son yıllarda kaya süreksizliklerinin yüzey pürüzlülüğü, zeminleri oluşturan minerallerin şekilsel özellikleri, fay düzlemlerinin ve kırıkl1çatlaklı ortamların karmaşı geometrilerinin sayısal ifadesi için fraktal boyut teorisi güvenilir ve pratik bir yöntem olması açısından tercih edilmektedir (örn. Barton vd., 1995; Gimknez vd., 1997; Sahimi, 2011; Ghanbarian vd., 2015).

İnce taneli zayıf bir matriks (bağlayıcı malzeme) içerisinde daha sağlam blokların bulunduğu pekişmiş ya da gevşek haldeki kaya kütleleri "bimkaya (bimrock)" ya da "hamurda kaya" olarak tanımlanmaktadırlar (Medley, 1994; Medley ve Lindquist, 1995; Medley, 2002). Bu tür kaya kütlelerinin yanı sıra, matriksin zeminden oluşması ve kaya bloklarını kolaylıkla matriksten ayrılması halinde bu çökeller bimzemin ya da zeminkaya karışımı (SRM) (Xu vd., 2007; Coli vd., 2011; Xu vd., 2011; Whang vd., 2016; Zhang vd., 2016) olarak da bilinmektedirler. İri taneli piroklastik kayalar, volkanoklastik kayalar, makaslanmış serpantinler, zeminkaya karışımları, melanjlar ve fay kayaları gibi bloklar içeren kaya kütleleri tipik hamurda kaya örnekleri olarak gösterilmektedirler (Medley, 1994; Lindquist ve Goodman, 1994). Hamurda kayalar, heterojen yapıları ve kisa mesafelerde oldukça değişken olabilen blok dağılımları sebebiyle mühendislik uygulamaları açısından problemlere neden olan kaya kütleleridir. Bu nedenle, hamurda kayaların içinde/üzerinde inşa edilecek yapılarda gelişebilecek sorunların belirlenmesi ve bu sorunların giderilmesi için bu tür kaya kütlelerinin makaslama davranışııın araştırılması ve makaslama dayanımının belirlenmesi oldukça önemlidir.

Son yıllarda, artan mühendislik uygulamalarının gereklilikleri doğrultusunda, hamurda kayalar araştırmacıların ilgisini çekmeye ve popüler bir araştırma konusu olmaya başlamıştır. Buna rağmen, önceki çalışmaların tümü değerlendirildiğinde, hamurda kayaların jeo-mühendislik karakterizasyonuna ilişkin konuların araştııılmasında halen önemli eksiklikler söz konusudur. Özellikle, laboratuvar ve arazi deneyleri için örnek hazırlamadaki zorluklar nedeniyle bu tür kaya kütleleri diğer kayalara oranla daha az araştırllan ve dolayısıyla jeo-mekanik açıdan belirsizliği çok olan bir kaya türüdür. Hamurda kayaların en önemli özelliği bloklar içermeleri nedeniyle heterojen bir yapıya sahip olmalarıdır. Hacimsel blok oranı, blok boyutu dağılımı, blok yüzeylerinin pürüzlülüğü, matriksin dayanımı ve kaynaklanma miktarı gibi içsel ve yapısal özellikler bu türdeki kaya kütlelerinin fiziksel durumunu kontrol 
eden ve dayanımını etkileyen en önemli parametrelerdir. $\mathrm{Bu}$ çalışmada "blok boyutu dağılımı" ve "blok yüzeylerinin pürüzlüğüu” olmak üzere iki parametre dikkate alınmış ve bunların makaslama dayanım parametrelerine olan etkisi araştırılmıştır. Her iki parametreyi de matematiksel olarak ifade etmek için fraktal boyut geometrisi kullanılmıştır. Fraktal boyut hesaplamaları uygulanarak hamurda kayanın içerdiği blokların; blok boyutu dağılımı "parçalanma fraktal boyutu, $\mathrm{D}_{\mathrm{F}}$ " ile blok yüzeylerinin pürüzlüğü ise "pürüzlülük fraktal boyutu, $\mathrm{D}_{\mathrm{R}}$ " ile sayısal olarak boyutlandırılmıştır.

Altınsoy (2006), santimetre boyutunda kırarak hazırladığ 1 andezit blokları ve laboratuvarda çimentoyla hazırladığ 1 bağlayıcı malzemeyi karıştırarak yapay hamurda kaya örnekleri hazırlamıştır. Araştırmacı, farklı hacimsel blok oranına (HBO) sahip yapay hamurda kaya örnekleri üzerinde üç eksenli sıkışma dayanımı deneyleri uygulamıştır. Altınsoy (2006), HBO’nun azalmasına koşut olarak içsel sürtünme açısının arttığını, kohezyonun ise azaldığını belirlemiştir. Coli vd. (2011), HBO'nun \%18 ile \%26 arasındaki değerlerinde kohezyonun ani bir şekilde azaldığını ve bu düşük değerlerde kohezyonunla HBO arasında anlamlı bir ilişki olmadığını belirlemişlerdir. HBO ile makaslama dayanımı parametreleri arasındaki ilişkilerin incelendiği bazı önceki çalışmalar olmasına rağmen, blokların fraktal boyutu ile makaslama dayanım parametreleri arasındaki ilişkilerin araştırıldığ 1 herhangi bir önceki çalışmaya rastlanmamıştır. Avsar (2020) ise Sille (Konya)'daki pekişmiş volkanik hamurda kayaların tek eksenli sıkışma dayanımının tahmini için bağımsız parametre olarak HBO ve blok sayısının $\left(B_{N}\right)$ yanı sira blokların fraktal boyutlarını da kullanmıştır. $\mathrm{Bu}$ çalışmaların yanı sıra, Zorlu (2008) tarihi Olba (Mersin) şehrindeki yapılarda yapı taşı olarak kullanılan kayaların bozunma derecesini tayin etmek için Schmidt deneyleri uygulamış ve farklı bozunma derecelerindeki yapı taşlarının fraktal boyutlarını belirlemiştir.

$\mathrm{Bu}$ çalışmada, tipik bir pekişmiş hamurda kayanın içerdiği bloklarının pürüzlülük ve parçalanma fraktal boyutlarının belirlenmesi ve bu özelliklerin kaya kütlesinin makaslama dayanıma etkisinin incelenmesi amaçlanmıştır. Bu amaçla, üç eksenli sıkışma deneyleriyle kaya kütlesinin makaslama dayanımı parametreleri kohezyon (c) ve içsel sürtünme açısı $(\phi)$ belirlenmiştir. Bununla birlikte, hamurda kayanın içerdiği blokların blok boyutu dağılımı ve blok yüzeylerinin pürüzlülügünün fraktal boyutlarının hesaplanması için sayısal görüntü işleme analizleri ve bazı hesaplamalar yapılmıştır. Tüm parametreler belirlendikten sonra, blokların fraktal geometrilerinin makaslama dayanımına etkisi grafikler yardımıyla ilişkiler incelenerek değerlendirilmiştir.

\section{HAMURDA KAYANIN YAPISI VE GENEL ÖZELLIKKLERİ}

$\mathrm{Bu}$ çalışmada, Konya'daki Tatköy Mahallesi'nin batısında yüzeylenen piroklastiklerden (Şekil 1) örnekler alınmış ve bu çökellerin kuru birim ağırlık, tek eksenli sıkışma dayanımı, kohezyon ve içsel sürtünme açısı gibi bazı fiziksel ve jeo-mekanik özellikleri belirlenmiştir. Konya'da birçok yerde yüzeylenen Miyosen-Pliyosen yaşlı Sulutaş volkanitleri ve Erenler Dağı-Alacadağ volkanik kompleksi; andezitik dayklar, domlar, akmayağma çökelleri, epivolkanoklastikler ve lav akıntılarından oluşmaktadırlar (Eren, 1993; Özkan, 1998). Bu piroklastikler çok aşamalı bir volkanik faaliyetin çökelleridir (Keller vd., 1977; Besang vd., 1977). Tatköy, Sarayköy ve Sille'deki akma-yağma çökelleri, volkanoklastik 
Avşar

çökeller ve tüfitler Sulutaş volkanitleri olarak bilinmektedirler (Eren, 1993; Özkan, 1998). Tatköy civarındaki bazı piroklastikler, blokkül akma-yağma çökelleri olup, bu birimler genellikle andezit/dasit blokları ve bu blokların içinde bulunduğu kül-lapilli boyutundaki volkanik kökenli bağlayıcı malzemeden oluşmaktadırlar. Özkan (1998) bu birimlerin yaşını Geç Miyosen-Erken Pliyosen olarak belirlerken, ${ }^{40} \mathrm{Ar}-{ }^{39} \mathrm{Ar}$ çözümlemeleri yapan Koç vd. (2012) ise $11.88 \pm 0.26$ ile $11.67 \pm 0.24$ My arasında değiştiğini belirlemişlerdir. Söz konusu volkanik kayaları kaya mühendisliği açısından değerlendirildiğinde "düşük dayanıma sahip pekişmiş volkanik hamurda kaya" olarak tanımlamak mümkündür (Şekil 1b). Tatköy mahallesinin yaklaşık $1 \mathrm{~km}$ batısındaki 2 lokasyonda örnekleme çalışmaları gerçekleştirilmiştir. Bu kapsamda, yamaçlardan koparak düşen yaklaşı $0.5-1 \mathrm{~m}^{3}$ boyutlarındaki iri kaya blokları toplanarak laboratuvara nakledilmiştir. Laboratuvarda bu bloklardan $64 \mathrm{~mm}$ çapında karot örnekleri hazırlanmıştır. Arazi gözlemlerinde, araştırılan hamurda kaya kütlesinin içerdiği bloklar ve matriksin renk tonu ve şekil özellikleri açısından açık bir şekilde ayırt edilebilmektedir. $\mathrm{Bu}$ bileşenlerin kaya türü açısından tanımlanması amacıyla hem bloklardan hem de matriks kismından örnekler derlenerek ince kesitler hazırlanmıştır. İnce kesitlerde yapılan mikroskobik analizler sonucunda blokların andezit/dasit, matriksin ise kül-lapilli boyutundaki volkanik çökeller olduğu belirlenmiştir.

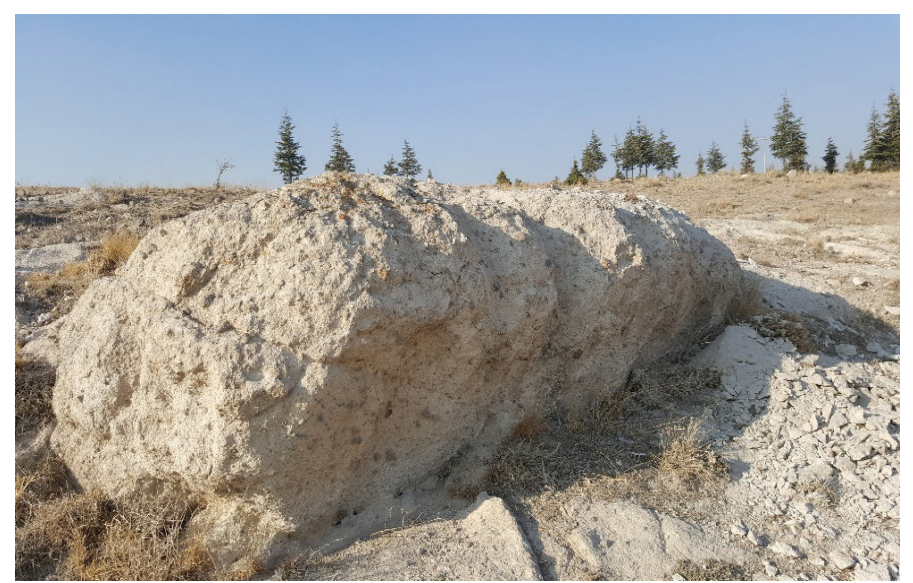

(a)

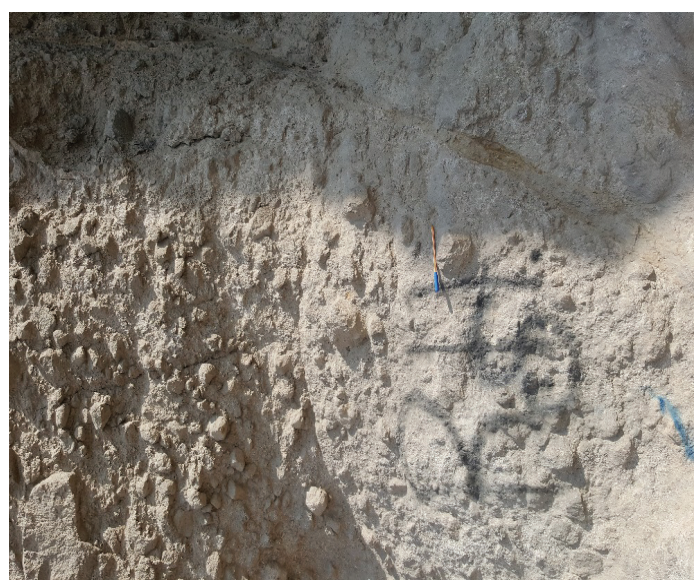

(b)

Şekil 1. Konya Tatköy Mahallesi’ndeki hamurda kayalara ait (a) bir yüzleğin ve (b) bloklar ve matriksin yakından görüntüsü.

Figure 1. View from (a) an outcrop and (b) a close-up view from blocks and matrix in the bimrocks in Tatköy District, Konya. 


\section{KAYA KÜTLESINNDEKİ BLOKLARIN FRAKTAL BOYUTU}

Mandelbrot (1982), fraktal kümeler olarak adlandırdığı geometrik ve rastlantısal (stokastik) karakterdeki matematiksel fonksiyon kümelerini incelemiştir. Topografik rölyefden süzülmeye kadar birçok doğal oluşumu benzeştirmek ya da modellemek için rastgele fraktal kümelerin istatistiksel modeller şeklinde kullanılabileceğini grafik gösterimler sunarak ortaya koymuştur. Rastgele ve rastgele olmayan fraktal fonksiyonlar sürekli olmalarına rağmen, bu fonksiyonların herhangi bir noktada en azından belirli bir ölçek aralığ1 için değişkenlik göstermemesi temel özellikleridir.

Doğal ya da yapay herhangi bir varlığın pürüzlülüğünü fraktal boyut teorisi ve bu teorinin içerdiği hesaplama yöntemleriyle sayısal olarak tanımlayabilmek mümkündür. Kabartılardan oluşan bir yüzeyin tek boyuttaki dikey kesitinin fraktal boyutu 1 ve 2 arasında değişirken, iki boyutlu bir yüzeyin fraktal boyutu ise 2 ile 3 arasında değişmektedir. Fraktal boyut (D)'nin en genel denklemi Eşitlik 1'de verilmiştir (Mandelbrot, 1982).

$\mathrm{D}=\log (\mathrm{N}) / \log [1 / \mathrm{r}(\mathrm{N})]$

Burada; $\mathrm{r}(\mathrm{N})$ benzerlik oran1, $\mathrm{N}$ ise benzerlik oranına (ya da ölçeğe) bağlı olarak üst üste çakışmayan ve birbirine benzer parçaların sayısıdır. $\mathrm{Bu}$ eşitlik kullanılarak, geometrik olarak üretilen çizgisel ya da düzlemsel desenlerin $\mathrm{D}$ değeri hesaplanabilmektedir (Şekil 2). Şekil 2a'daki birim uzunluk $r(N)=1 / 4$ oranıyla bölünmüş ve b'deki fraktal eğrisi $\mathrm{N}=8$ parçadan oluşmuştur. Şekil 1c'de ise aynı süreç tekrarlanma oranı $\mathrm{r}(\mathrm{N})=1 / 16$ ve $\mathrm{N}=64$ parça olacak şekilde Koch eğrisinin çizimi devam etmiştir. Böylece, bu çizgisel kırıklı eğrinin fraktal boyutu Eşitlik 1 kullanılarak, Eşitlik 2'deki gibi $\mathrm{D}=1.5$ olarak hesaplanır.

$\mathrm{D}=\log (64) / \log (16)=1.5$

\section{Kırıntılıların Dağılımının Fraktal Boyutu}

Mandelbrot (1982), parçalanmış ya da kırıntılı nesnelerin boyut dağılımının fraktal boyutunu belirlemek amaciyla Eşitlik 3'ü önermiştir. Bu eşitlik jeolojik açıdan kırıntılı ya da bloklu malzemelerin tane boyu dağılımının parçalanma fraktal boyutunu $\left(\mathrm{D}_{\mathrm{F}}\right)$ belirlemek amacıyla da kullanılmaktadır.

$\mathrm{N}(\mathrm{R}>\mathrm{r})=\mathrm{cr}^{-\mathrm{DF}}$

Burada; N(R>r) blokların r'den büyük R gibi bir çizgisel büyüklüğünün kümülatif frekans1, $\mathrm{D}_{\mathrm{F}}$ parçalanma fraktal boyutu ve c ise en büyük blok boyutuyla ilişkili bir katsayıdır.

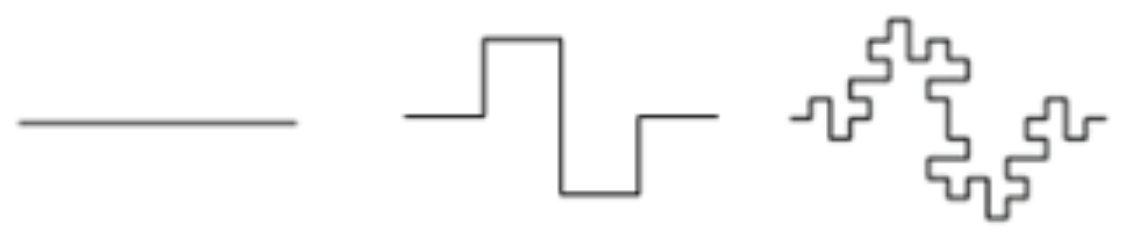

(a)

(b)

(c)

Şekil 2. Von Koch fraktal eğrisinin farklı ölçeklerdeki görüntüsü.

Figure 2. View of the Von Koch fractal curve at different scales. 
Avşar

Medley $(1994,2002)$ ve Medley ve Lindquist (1995) hamurda kayayı ilişkili olan mühendislik yapısının boyutlarını dikkate alarak blok/matriks sınır boyutlarını tanımlamışlardır. Buna göre, baraj temelinin genişliği, karot çapı, tünelin aynasının genişliği gibi boyutlar "karakteristik mühendislik boyutu, $\mathrm{L}_{\mathrm{c}}$ ” olarak tanımlanmıştır. Medley ve Lindquist (1995) en küçük ve en büyük blok boyutlarını Lc değerini dikkate alarak, en küçük blok boyutunu $\mathrm{d}_{\min }=0.05 \mathrm{~L}_{\mathrm{c}}$ ve en büyük blok boyutunu ise $\mathrm{d}_{\text {max }}=0.75 \mathrm{~L}_{\mathrm{c}}$ olarak önermişlerdir. Bu çalışmada, $\mathrm{L}_{\mathrm{c}}$ karot çap1 olup $\mathrm{D}=64 \mathrm{~mm}$ 'dir. Böylece, $\mathrm{d}_{\min }$ ve $\mathrm{d}_{\max }$ değerleri sirasiyla $3.2 \mathrm{~mm}\left(\mathrm{~d}_{\min }=64 * 0.05\right)$ ve $48 \mathrm{~mm}$ $\left(\mathrm{d}_{\max }=64 * 0.75\right)$ olarak belirlenmiştir. Sonuç olarak, $3.2 \mathrm{~mm}$ çapından daha küçük çapa sahip taneler matriks ve $3.2 \mathrm{~mm}$ ile $48 \mathrm{~mm}$ arasinda değişen çaplardaki taneler ise blok olarak değerlendirilmiştir.

Fotoğraflar ya da çizimler üzerinde uygulanan bir yöntem olan iki boyutlu sayısal görüntü işleme yöntemi kısa zaman alan, pratik ve düşük maliyetli bir uygulamadır. Fotoğraflar kullanılarak blokların kapladığı alanlar üzerinde sayısallaştırma yapılabilmesi için matriks ve bloklar arasında yeterli renk tonu zitlığının olmas1 gerekmektedir. Ancak, incelenen hamurda kayadaki blok ve matriksin renk tonları birbirine çok yakın olduğundan, fotoğraflar çekilerek bunların üzerinden sayısallaştırma yapılamamıştır. Bunun yerine, deneyler yapılmadan önce karot örneklerinin içerdiği blokların alansal dağılımının belirlenmesi amacıyla; karotlara şeffaf kağıtlar sarılarak blok sınırları tek tek elle çizilmiştir. Bu işlem her bir karotun yanal yüzey alanları ile alt ve üst dairesel kısımları için uygulanmıştır. Karotların yüzeyinde görünen blokların ölçekli olarak üstüne çizildiği şeffaf kağıtlar taranarak bilgisayar ortamına aktarılmıştır. Sayısal görüntü işleme analizleri kapsamında "Fiji-ImageJ"
(Schindelinvd., 2012) programı kullanılmıştır. Bu programa yüklenen her karotun görüntüsü ölçek kullanılarak "ölçek ayarlama (set scale)" aracı kullanılarak sayısallaştırılmıştır. Daha sonra, her bir bloğun kapladığ 1 alanın belirlenebilmesi için kenar çizgileri çizilmiş olan blokların içi siyah renkle boyanmıştır. Kalan beyaz alanlar ise matrikse ait alanlardır. Son aşamada, görüntüler 8-bit'e dönüştürülmüş ve tanecik analizleri aracı kullanılarak; karot örneklerinin içerdiği blokların alanı, çevre uzunluğu, kumpas (feret) çap1 gibi özellikleri tayin edilmiştir. Önceki çalışmalarda olduğu gibi (Haneberg, 2004; Sönmez vd., 2005; Kahraman vd., 2008; Coli vd., 2011;) alansal blok oranı değerleri hacimsel blok oranı (HBO) değerlerine eşit varsayılmıştır. Analiz sonuçlarına göre, karotların HBO değerleri \%30 ile \%44 arasında değişmektedir. Karotların içerdiği bloklara ait çap değerleri ve blok sayıları görüntü işleme analizlerinden elde edildikten sonra blok çapının frekans dağılımı grafikleri çizilmiştir. Bu log-log grafiklere ait eğrilerin denklemleri Eşitlik 3'e uygun şekilde kullanılarak her karotun $\mathrm{D}_{\mathrm{F}}$ değeri belirlenmiştir. Buna göre, karotların $\mathrm{D}_{\mathrm{F}}$ değerleri 1.436 ile 1.954 arasında değişmektedir. Blok boyutu dağılımına göre $\mathrm{D}_{\mathrm{F}}$ değerleri değerlendirildiğinde; görece iri bloklardan daha fazla sayıda ince bloklar içeren karotların $\mathrm{D}_{\mathrm{F}}$ değerleri yüksekken, buna karşın ince bloklardan daha fazla sayıda iri bloklar içeren örneklerin ise $\mathrm{D}_{\mathrm{F}}$ değerlerinin azaldığ 1 belirlenmiştir.

\section{Alan-Çevre (A-Ç) Yöntemi}

Mandelbrot (1977) düzlemsel yüzeylerin fraktal geometrilerini incelemek amaciyla Alan-Çevre (A-Ç) yöntemini önermiştir. A-Ç yöntemi bir şeklin çevresinin kıvrımlanma ya da pürüzlülük derecesinin karışıklığı hakkında bilgi verir. Bu karışıklık, Eşitlik 4'deki çevrenin 
fraktal boyutu (D) ile karakterize edilebilir. A-Ç yöntemine ait denklem Eşitlik 4'de verilmiştir. Daire ve kare gibi çevreleri düz olan geometrik şekiller $C ̧ \sim \mathrm{A}^{1 / 2}$ ile ifade edilirler ve bu şekillerin $D$ değeri çizgisel unsurların fraktal boyutu olan $\mathrm{D}=1$ 'e eşittir. Eğer bir şeklin çevresi çevrelediği alanın içini dolduracak kadar pürüzlü ya da kıvrımlı olursa bu durumda D değeri 2'ye yaklaşır.

$\mathrm{c}=(\mathrm{C})^{1 / \mathrm{DR}} /(\mathrm{A})^{1 / 2}$

Burada; c benzer fraktal şekiller için bir sabit, $\mathrm{D}_{\mathrm{R}}$ ise pürüzlülük fraktal boyutudur. $\mathrm{Bu}$ eşitliğin her iki tarafının logaritması alındığında alan ve çevre arasında doğrusal bir ilişki elde edilmektedir. Böylece, $\mathrm{m}$ bu ilişkiye ait doğrunun eğimi olup, $D_{R}=2 / \mathrm{m}$ olarak hesaplanır. Hesaplamalar sonucunda, hamurda kaya karotlarının içerdiği blokların $\mathrm{D}_{\mathrm{R}}$ değerlerinin 1.029 ile 1.061 arasında değiştiği belirlenmiştir.

\section{HAMURDA KAYANIN DAYANIMI VE FRAKTAL BOYUT İLIŞKILERI}

\section{Hamurda Kayanın Makaslama Dayanımı ve Tek Eksenli Sıkışma Dayanımı}

$\mathrm{Bu}$ çalışmada örnek hazırlama çalışmaları Konya Teknik Üniversitesi Kaya Mekaniği Laboratuvarı'nda gerçekleştirilmiş olup, karotlar alınırken bazı güçlüklerle karşılaşılmıştır. Dünya genelinde hamurda kayalardan, özellikle matriksi zemin olan kaya kütlelerinden standartlara/ önerilmiş yöntemlere göre örselenmemiş örneklerin hazırlanması oldukça zordur. Örnek hazırlamada karşılaşılan sorunlar nedeniyle bazı araştırmacılar arazi makaslama deneylerini uygulamışlardır (Li vd., 2004; Xu vd., 2007; Coli vd., 2011). Diğer taraftan, hamurda kayaların makaslama dayanımını araştıran ve standartlara uygun özelliklerde örnek hazırlayabilen araştırmacılar (Lindquist, 1994; Goodman ve Ahlgren, 2000; Sönmez vd., 2006; Altınsoy, 2006; Kahraman vd., 2008; Kalender vd., 2014; Zhao ve Liu, 2018) laboratuvarda dayanım deneyleri yapmışlardır. $\mathrm{Bu}$ çalışmada ise laboratuvarda karot alınırken birçok örnek blok matriks temas yüzeylerinin olduğu kısımlardan parçalanarak dağılmıştır. Karot alırken zayıf kayalardan örnek alınması için üretilen elmas uçlu karotiyer kullanılmıştır. Buna ek olarak, karot alma makinesinde hızlı ve yavaş dönme hızlarının her ikisinin de denenmesine rağmen birçok karot daha kaya örneklerinden çıkarılmadan ya da alt ve üst yüzeyleri düzeltilirken parçalanmışlardır. $\mathrm{Bu}$ nedenle, çalışma kapsamında standartlara uygun boyut ve özelliklerde sınırlı sayıda örnek hazırlanabilmiştir. Örneklemeler yapılırken malzeme özelliklerinin belirgin biçimde farklılaşmaması için arazideki dar bir alanda örneklemelerin gerçekleştirilmesine özen gösterilmiştir. Makaslama deneyleri için 27 ve tek eksenli sıkışma (UCS) deneyleri için 10 adet olmak üzere toplam 37 adet hamurda kaya karot örneği hazırlanmıştır (Şekil 3c). Ayrıca, hamurda kaya kütlesinde yer yer çok iri blokların olduğu bölgeler ayırt edilmiş ve içinden karot alınabilecek kadar iri blokların yoğun olduğu yerlerden örnekler alınmıştır. Bununla birlikte, matriksin yoğun olduğu kısımlardan da karot örnekler alınması için kaya parçaları toplanmıştır. Böylelikle, hamurda kayanın matriks ve blok bileşenlerine ait kısımlardan ayrı ayrı olmak üzere 6'şar adet toplam 12 karot örneği (Şekil 3a ve 3b) derlenmiştir. 
Avşar

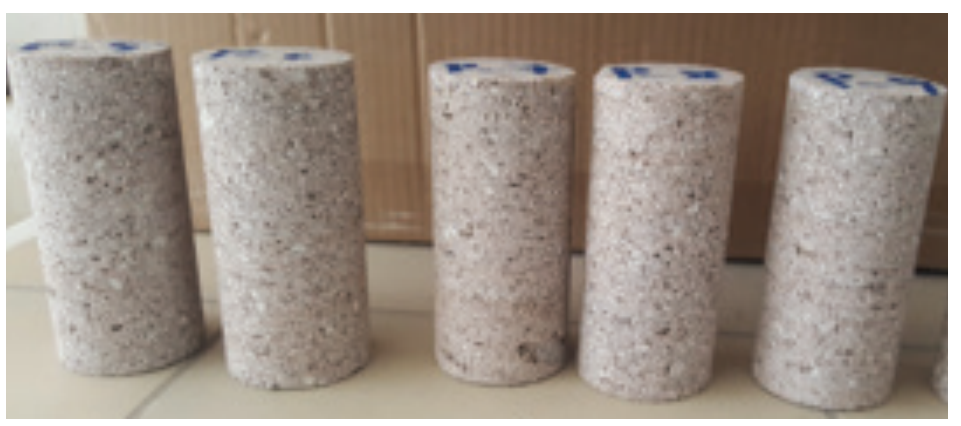

(a)

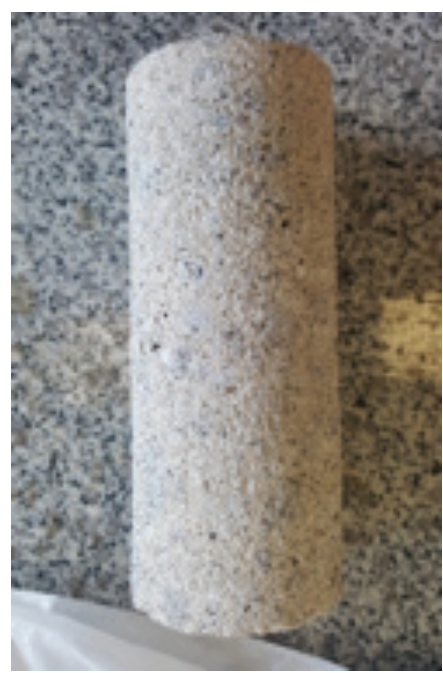

(b)

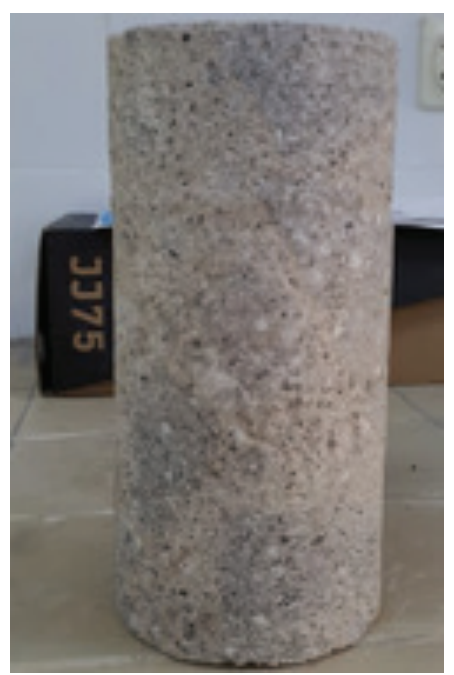

(c)

Şekil 3. Laboratuvarda hazırlanan karotlara ait görüntüler (a) blok bileşeninden alınan UCS deneyi için hazırlanan karotlar, (b) matriks bileşenine ait bir örnek, (c) makaslama deneyi için hazırlanan bir hamurda kaya örneği.

Figure 3. Images of the cores prepared in the laboratory, (a) cores prepared for the UCS tests taken from the block component, (b) a specimen from the matrix component, (c) a bimrock specimen prepared for the shear test.

$\mathrm{D}_{\mathrm{R}}$ ve $\mathrm{D}_{\mathrm{F}}$ 'ninc ve $\phi$ üzerindeki etkisinin netbir şekilde gözlenebilmesi amaciyla HBO değerleri birbirine yakın olan karot örnekleri deneylere tabi tutulmuştur. Bu sayede, HBO'nun etkisi en aza düşürülerek, direk olarak blok şeklinin ve blok boyutu dağılımının dayanım üzerindeki etkisinin ortaya konulması planlanmıştır. Üç eksenli sıkışma dayanımı deneyleri için 3'er adet örnekten oluşan deney setleri oluşturulmuştur. HBO değerleri \%30 ile \%44 arasında değişen toplam 27 örnek üzerinde 9 set üç eksenli sıkışma dayanımı deneyi Ankara Üniversitesi
Jeoloji Mühendisliği Bölümü Mühendislik Jeolojisi Laboratuvarı'nda gerçekleştirilmiştir. Dayanım deneyleri için ISRM (2007) tarafından önerilen yöntemler esas alınmış ve deneyler sabit yükte en yüksek kapasitenin $\% 0.005$ 'i kadar hassasiyette çalışan $500 \mathrm{kN}$ kapasiteli bir kaya presi kullanılarak yapılmıştır. Üç eksenli sıkışma dayanımı deneylerinde $0.5,1.0$ ve $1.5 \mathrm{MPa}$ çevre basınçları uygulanmış olup, Mohr-Coulomb yenilme kriterine uygun olarak c ve $\phi$ değerleri hesaplanmıştır. 
Hamurda kaya ve bileşenlerinin kuru birim ağırlığ kohezyon ve içsel sürtünme açısı değerleri bazı istatistiksel sonuçlarla birlikte Çizelge 1'de sunulmuştur. Deney sonuçlarına göre, hamurda kayanın kohezyonu 0.59 ile $1.93 \mathrm{MPa}$ arasında ve içsel sürtünme açısı değerleri ise $32^{\circ}$ ile $48^{\circ}$ arasında değişmektedir. Makaslama deneylerinin yanı sira, hamurda kayanın kohezyonunun matriksin dayanımından da etkilenebileceği göz önüne alınarak, matriks dayanımının hangi aralıkta değiştiğinin gözlenmesi için matriks örneklerinin tek eksenli sıkışma dayanımı (UCS) belirlenmiştir. Buna göre, 6 adet matriks karotunun UCS değerlerinin 3.49 ile $4.68 \mathrm{MPa}$ arasında değişim gösterdiği belirlenmiştir. UCS değerlerinin standart sapması oldukça düşük olan (Çizelge 1) olan matriksin dayanımının dar bir aralıkta değişim gösterdiği anlaşılmıştır. Hamurda kayanın blok bileşenine ait karotların UCS değerlerinin ise 8.45 ile $12.82 \mathrm{MPa}$ arasında değiştiği saptanmıştır. $\mathrm{Bu}$ sonuçlar dikkate alınarak, kohezyon ile fraktal boyut arasındaki ilişkiler değerlendirilirken örneklerin matriks değerlerinin neredeyse aynı olduğu varsayımı yapılmıştır. Son olarak, 10 adet hamurda kaya örneğine tek eksenli sıkışma dayanımı deneyleri uygulanmıştır. Deney sonuçlarına göre, hamurda kayanın UCS değerleri 4.69 ile $7.98 \mathrm{MPa}$ arasında değişmektedir.

\section{$D_{F}$ ve $D_{R}$ ile Makaslama Dayanım Parametreleri Arasındaki İlişkiler}

Hamurda kaya örneklerin $\mathrm{D}_{\mathrm{F}}$ ve $\mathrm{D}_{\mathrm{R}}$ değerleri ile c ve $\phi$ arasındaki ilişkiler incelenmiştir. Şekil 4'deki grafiklerden de görüldüğü gibi söz konusu parametreler arasında belirtme katsayıları $\left(\mathrm{R}^{2}\right)$ yüksek doğrusal ilişkilerin olduğu belirlenmiştir. Hamurda kayanın içerdiği blokların $D_{R}$ 'si $\operatorname{artarken} \phi$ değerleri de artış göstermektedir. Buna karşın, $\mathrm{D}_{\mathrm{R}}$ ile c arasında ters orantılı (negatif) doğrusal bir ilişkinin olduğu görülmüştür. Diğer taraftan, $\mathrm{D}_{\mathrm{F}}$ ile olan ilişkileri incelediğimizde, $\mathrm{D}_{\mathrm{F}}$ ile $\phi$ arasında pozitif doğrusal bir ilişki varken, $\mathrm{D}_{\mathrm{F}}$ ile $\mathrm{c}$ arasında negatif doğrusal bir ilişki olduğu belirlenmiştir. Öneklerin HBO değerlerinin ve matriks dayanımlarının birbirlerine çok yakın oldukları dikkate alındığında, blokların fraktal boyut geometrilerinin c ve $\phi$ 'yi oldukça önemli oranda etkilediği Şekil 4'teki grafiklerde görülen doğrusal ilişkiler ve bu ilişkilere ait $\mathrm{R}^{2}$ değerlerinden de anlaşılmaktadır.

Çizelge 1. Hamurda kaya ve bileşenlerinin kuru birim ağırlığ

Table 1. Dry unit weight and geo-mechanical properties of the bimrock and its components.

\begin{tabular}{|c|c|c|c|c|c|c|}
\hline $\begin{array}{c}\text { Hamurda kaya ve } \\
\text { bileşenleri }\end{array}$ & Özellik & Örnek sayısı & En küçük & En büyük & Ortalama & Standart sapma \\
\hline \multirow{2}{*}{ Hamurda kaya } & $\mathrm{UCS}(\mathrm{MPa})$ & 10 & 4.69 & 7.98 & 6.42 & 1.04 \\
\hline & $\gamma_{\text {kuru }}\left(\mathrm{kN} / \mathrm{m}^{3}\right)$ & 10 & 15.35 & 17.94 & 16.42 & 0.86 \\
\hline \multirow{2}{*}{ Hamurda kaya } & $\mathrm{c}(\mathrm{MPa})$ & 27 & 0.59 & 1.93 & 1.33 & 0.43 \\
\hline & $\phi(\mathrm{kPa})$ & 27 & 32 & 48 & 40 & 5.46 \\
\hline \multirow{2}{*}{ Matriks } & $\mathrm{UCS}(\mathrm{MPa})$ & 6 & 3.49 & 4.68 & 4.04 & 0.41 \\
\hline & $\gamma_{\text {kuru }}\left(\mathrm{kN} / \mathrm{m}^{3}\right)$ & 6 & 14.72 & 16.50 & 15.76 & 0.55 \\
\hline \multirow{2}{*}{ Bloklar } & $\mathrm{UCS}(\mathrm{MPa})$ & 6 & 8.45 & 12.82 & 10.45 & 1.53 \\
\hline & $\gamma_{\text {kuru }}\left(\mathrm{kN} / \mathrm{m}^{3}\right)$ & 6 & 17.67 & 19.38 & 18.14 & 0.59 \\
\hline
\end{tabular}

UCS: Tek eksenli sıkışma dayanımı, $\gamma_{\text {kuru }}$ : Kuru birim ağırlık; c: Kohezyon; $\phi$ : İçsel sürtünme açısı 
Avşar

$\mathrm{Bu}$ ilişsilerden özellikle, $\mathrm{D}_{\mathrm{R}}$ ve $\phi$ arasındaki pozitif ilişkinin belirtme katsayısı $\left(\mathrm{R}^{2}=0.7686\right)$ oldukça yüksektir. Bu iki parametre arasındaki ilişkiye göre; yüksek $D_{R}$ değerlerine sahip ve dolayısıyla pürüzlülüğü daha yoğun olan blok yüzeyleri içsel sürtünme açısını yükseltmektedir. Diğer taraftan, $\mathrm{D}_{\mathrm{R}}$ 'nin artmasiyla temas yüzeylerinin yüzey alanlarının genişlediği ve böylece kaya kütlesini gevşeten zayıflık zonlarının artmasına bağlı olarak kohezyonun

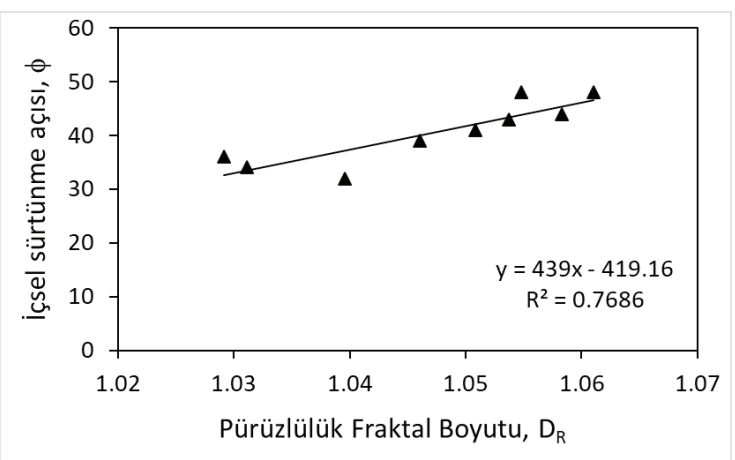

(a)

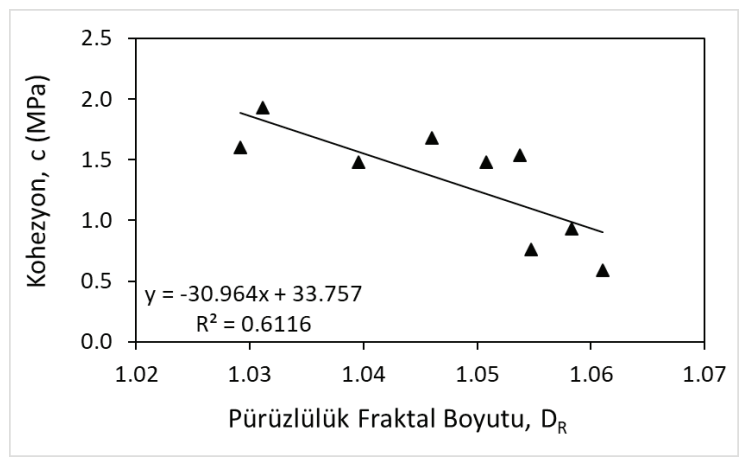

(c) azaldığ1 anlaşılmaktadır. Daha önce de belirtildiği gibi, görece çok sayıda ince bloklar içeren örneklerin $\mathrm{D}_{\mathrm{F}}$ değerleri yüksek iken, az sayıda iri bloklar içeren örneklerin $\mathrm{D}_{\mathrm{F}}$ değerleri daha düşüktür. Buna göre, $\mathrm{D}_{\mathrm{F}}$ ile c arasındaki ilişki değerlendirildiğinde, blokların sayıca artmasıyla kayayı zayıflatan zayıflık zonlarının (temas yüzeylerinin) da arttığı ve bunun da kaya kütlesini gevşetmesiyle c’yi düşürmüş̧ür.

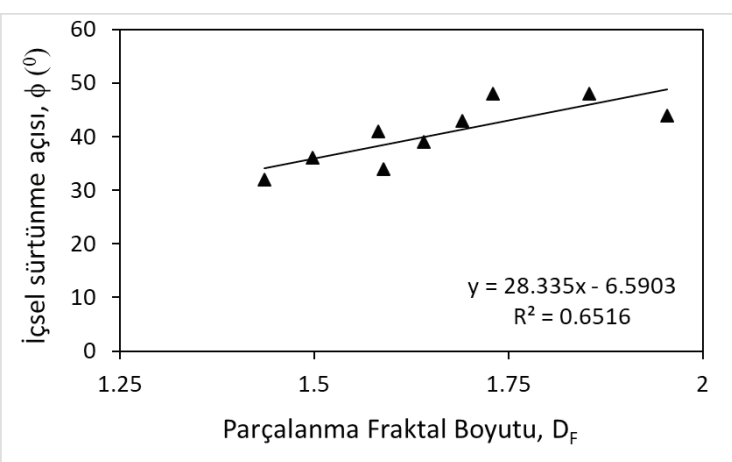

(b)

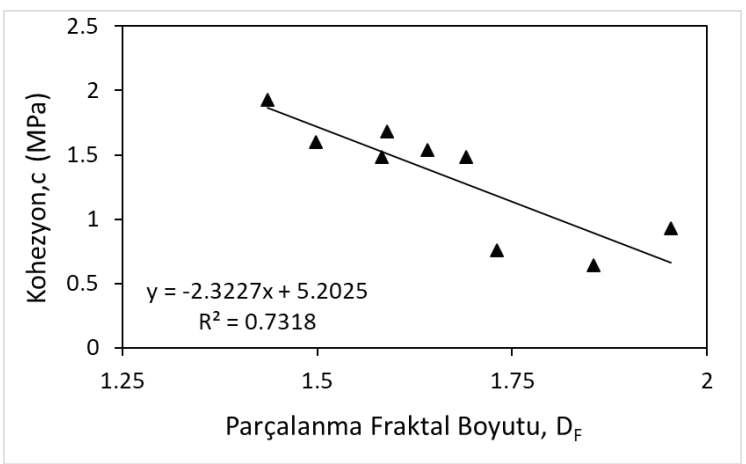

(d)

Şekil 4. Hamurda kayanın içsel sürtünme açısı ile (a) $D_{R}$, (b) $D_{F}$ ve kohezyon ile (c) $D_{R}$ ve (d) $D_{F}$ arasındaki ilişkiler ve bu ilişkilerin belirtme katsayıları $\left(\mathrm{R}^{2}\right)$.

Figure 4. The relationships between internal friction angle of the bimrock and (a) $D_{R}$, (b) $D_{F}$ and the relationships between cohesion and (c) $D_{R}$ ve (d) $D_{F}$ and coefficients of determination $\left(R^{2}\right)$ of these relationships. 


\section{SONUÇLAR VE ÖNERÍLER}

Son dönemlerde, örnek hazırlama ile ilgili zorluklar nedeniyle hamurda kayaların dayanım ve deformasyonları ile bazı fiziksel özellikleri arasındaki ilişkilerin araştırılmasına yönelik çalışmalar yapılmaktadır. Bu çalışmada ise, tipik bir pekişmiş volkanik hamurda kaya olan Tatköy piroklastiklerinin makaslama dayanımı parametreleri ile hamurda kaya içindeki blokların fraktal boyutları arasındaki ilişkiler araştırılmıştır. Bu kapsamda, hamurda kayanın kohezyonunun 0.59 ile $1.93 \mathrm{MPa}$ arasinda ve içsel sürtünme açısı değerlerinin ise $32^{0}$ ile $48^{0}$ arasında değiştiğibelirlenmiştir. HBO değerlerive matriks dayanımı birbirine yakın olan örneklerin, kohezyon ve içsel sürtünme açısı değerlerinin nispeten geniş aralıklarda değişim göstermesinin nedeninin kaya kütlesinin içerdiği blokların özelliklerinden kaynaklandığ1 düşünülmüştür. Blokların $\mathrm{D}_{\mathrm{R}}$ değerleri 1.029 ile 1.061 arasında değişirken, $\mathrm{D}_{\mathrm{F}}$ değerleri ise 1.436 ile 1.954 arasında değişmektedir. $D_{R}$ ve $\phi$ arasındaki pozitif ilişkiye göre, blok pürüzlülüğün artması kaya kütlesinin içsel sürtünme açısını artırmaktadır. $\mathrm{D}_{\mathrm{F}}$ ile $\mathrm{c}$ arasında belirtme katsayısı oldukça yüksek negatif ve doğrusal bir ilişki elde edilmiş olup, $\mathrm{D}_{\mathrm{F}}$ 'nin c'yi etkileyen önemli bir parametre olduğu belirlenmiştir. Son olarak, sirasıyla $D_{F}$ ile $\phi$ ve $D_{R}$ ile c arasinda pozitif ve negatif doğrusal ilişkiler elde edilmiştir. Farklı türde ve kökene sahip hamurda kayaların ya da bim zeminlerin içerdikleri blokların fraktal boyutunun makaslama dayanım parametrelerine etkisinin araştırılması büyük önem taşımaktadır. İleride yapılacak olan çalışmalarda örneklerin hazırlanabilmesi durumunda bu özelliklerin dayanıma etkisinin laboratuvarda belirlenerek araştırılması, laboratuvar örneklerinin alınamaması durumunda ise arazi deneyleri yapılarak araştırılması önerilmektedir.

\section{KAYNAKLAR}

Altınsoy, H., 2006. Matriks içinde blok içeren kayaların makaslama dayanımının belirlenmesi için fiziksel model esaslı bir araştırma. Hacettepe Üniversitesi Fen Bilimleri Enstitüsü, Ankara, Yüksek Lisans Tezi, 91s (yayımlanmamış).

Avsar, E., 2020. Contribution of fractal dimension theory into the uniaxial compressive strength prediction of volcanic welded bimrock. Bulletin of Engineering Geology and the Environment,79, 3605-3619.

Barton, C.C., Paul, R., Pointe, L., 1995. Fractals in the Earth Sciences. Plenum, NY.

Besang, C., Eckhardt, F. J., Harre, W., Kreuzer, H., Müller, P., 1977. Radiometrische altersbestimmungen an Neogenen eruptivgesteinen der Turkei. Geologisches Jahrbuch, B. 25, 3-36.

Coli, N., Berry, P., Boldini, D., 2011. In-situ nonconventional shear tests for the mechanical characterisation of a bimrock (BimTest). International Journal of Rock Mechanics and Mining Sciences, 48, 95-102.

Eren, Y., 1993. Eldeş-Derbent-Tepeköy-Söğütözü (Konya) arasının Jeolojisi. Selçuk Üniversitesi Fen Bilimleri Enstitüsü, Konya, Doktora Tezi, 224s (yayımlanmamış) .

Ghanbarian, B., Hunt, A.G., Skinner, T.E., Ewing, R.P., 2015. Saturation dependence of transport in porous media predicted by percolation and effective medium theories. Fractals, 23(1), 1540004 (14 pages).

Gimknez, D., Perfect, E., Rawls, W.J., Pachepsky, Y., 1997. Fractal models for predicting soil hydraulic properties. Engineering Geology, 48, 61-83.

Goodman, R.E., Ahlgren, C.S., 2000. Evaluating safety of concrete gravity dam on weak rock Scott Dam. Journal of Geotechnical Geoenvironmental Engineering, 126, 429-442.

Haneberg, W.C., 2004. Simulation of 3D block populations to characterize outcrop sampling bias in bimrocks. Felsbau Rock and Soil Engineering-Journal of Engineering Geology, Geomechanics and Tunnelling, 22(5), 19-26. 
Avşar

ISRM, 2007. Suggested methods prepared by the commission on testing methods. In: Ulusay R, Hudson JA, eds. The Complete ISRM Suggested Methods for Rock Characterization, Testing and Monitoring: 1974-2006. Ankara, Turkey: International Society for Rock Mechanics, Compilation Arranged by the ISRM Turkish National Group, Kozan Ofset.

Kahraman, S., Alber, M., Fener, M., Gunaydin, O., 2008. Evaluating the geomechanical properties of Misis fault breccia (Turkey). International Journal of Rock Mechanics and Mining Sciences, 45(8), 1469-14.

Kalender, A., Sonmez, H., Medley, E., Tunusluoglu, C., Kasapoglu, K.E., 2014. An approach to predicting the overall strengths of unwelded bimrocks and bimsoils. Engineering Geology, 183, 65-79.

Keller, J., Jung, D., Burgath K., Wolf, F., 1977. Geologie undpetrologie des Neogenen kalkalkalivulkanismus von Konya (Erenler Dağ-Alaca Dağ-Massiv Zentral-Anatolian). Geology Jb B, 25, 37-117.

Koç, A., Kaymakçı, N., Hinsbergen, D. J. J. V., Kuiper, K. F., Vissers, R. L. M., 2012. TectonoSedimentary evolution and geochronology of the Middle Miocene Altınapa Basin and implications for the Late Cenozoic uplift history of the Taurides, southern Turkey. Tectonophysics, 532$535,134-155$.

Li, X., Liao, Q.L., He, J.M., 2004. In-situ tests and a stochastic structural model of rock and soil aggregate in the Three Gorges Reservoir area. China International Journal of Rock Mechanics and Mining Sciences, 41(3), 702-707.

Lindquist, E.S., Goodman, R.E., 1994. The strength and deformation properties of a physical model mélange. Proceedings 1st North American Rock Mechanics Symposium, Austin, Texas, pp. 843850 .

Mandelbrot, B.B., 1967. How long is the coast of Britain? Statistical self-similarity and fractional dimension. Science, 156, 636-638.
Mandelbrot, B.B., 1977. Fractals Form, Chance and Dimension. Freeman, San Francisco, 365p.

Mandelbrot, B.B., 1982. The Fractal Geometry of Nature. W. H. Freeman, San Francisco, California, 460p.

Medley, E., 1994. The engineering characterization of melanges and similar Block-in-Matrix Rocks (BIMRock's). (Ph.D. Thesis) University of California, Berkeley.

Medley, E.W., 2002. Estimating block size distributions of melanges and similar block-inmatrix rocks (bimrocks). Proceedings of the 5th North American Rock Mechanics Symposium (NARMS), pp. 509-606.

Medley, E.W., Lindquist, E.S., 1995. The engineering significance of the scale-independence of some Franciscan melanges in California. In: Daemen JK, Schultz RA, editors. Proceedings of the 35 th US rock mechanics symposium. Rotterdam: Balkema, pp. 907-14.

Özkan, A. M., 1998. Konya batısındaki Neojen çökellerinin stratigrafisi ve sedimantolojisi. Selçuk Üniversitesi Fen Bilimleri Enstitüsü, Konya, Doktora Tezi, 228s (yayımlanmamış).

Özkan, M.A., 2017. Küçükmuhsine-Sulutaş (Konya batısı, Türkiye) çevresindeki karasal neojen çökellerinin (Geç Miyosen-Erken Pliyosen) stratigrafisi. El-Cezerî Journal of Science and Engineering, 4(3), 382-410.

Sahimi, M, 2011. Flow and Transport in Porous Media and Fractured Rock: From Classical Methods to Modern Approaches. Wiley-VCH, Weinheim, Germany, 733p.

Schindelin, J., Arganda-Carreras, I., Frise, E. et al., 2012. Fiji: an open-source platform for biological-image analysis. Nature Methods, 9(7): 676-682.

Sönmez, H., Tuncay, E., Gökçeoğlu, C., Nefeslioğlu, H., 2005. Matriks İçinde Blok İçeren Kayaçların Deformasyon Modülünün Saptanabilmesine Yönelik Fotoanaliz Destekli Yaklaşımların Geliştirilmesi. TÜBİTAK Yer, Deniz, Atmosfer Bilimleri ve Çevre Araştırma Grubu, Proje no. 102 Y033. 
Sönmez, H., Altınsoy, H., Gökceoglu, C., Medley, E.W., 2006. Considerations in developing an empirical strength criterion for bimrocks. 4th Asian Rock Mechanics Symposium. Retrieved from http://bimrocks.com/bimsite/wp-content/ uploads/2010/07/Sonmez-et-al-2006.pdf.

Wang, Y., Li, X., Zheng, B., Mao, T.Q., Hu, R.L., 2016. Investigation of the effect of soil matrix on flow characteristics for soil and rock mixture. Geotechnique Letters, 6, 1-8.

Xu, W., Hu, R., Tan, R., 2007. Some geomechanical properties of soil-rock mixtures in the Hutiao Gorge area, China. Geotechnique, 3, 255-64.

Xu, W.J., Xu, Q., Hu, R.L., 2011. Study on the shear strength of soil-rock mixture by large scale direct shear test. International Journal of Rock Mechanics and Mining Sciences, 48(8), 12351247.
Zhang, H.Y., Xv, W.J., Yu, Y.Z., 2016. Triaxial tests of soil-rock mixtures with different rock block distributions. Soils Foundations, 56(1), 44-56.

Zhao, Y., Liu, Z., 2018. Study of material composition effects on the mechanical properties of soil-rock mixtures. Advances in Civil Engineering, 2018: 3854727.

Zorlu, K., 2008. Description of the weathering states of building stones by fractal geometry and fuzzy inference system in the Olba ancient city (Southern Turkey). Engineering Geology, 101, 124-133. 